\title{
Colorectal cancer conventional radiotherapy treatment technique with sparing the testicles
}

\author{
Hasan Osmic ${ }^{1}$, Semir Fazlic ${ }^{2}$ and Edis Dedovic ${ }^{2,3 *}$ \\ ${ }^{1}$ Oncology and Radiotherapy Clinic, University Clinical Centre Tuzla, Bosnia and Herzegovina \\ ${ }^{2}$ The department of medical physics and radiation protection, University Clinical Center Tuzla, Bosnia and Herzegovina \\ ${ }^{3}$ Department of physics, University of Tuzla, Bosnia and Herzegovina
}

\begin{abstract}
Colorectal cancer was the third most common cancer in 2012, with higher percentage of incidence in less developed countries. In a less developed countries usually conventional radiotherapy technique is used for treatment of colorectal cancer. Using this technique testicles receive a dose from scattered radiation, due to the divergence of fields towards the testicles. We tried to re-duce a testicular dose avoiding the divergence of fields towards the testicles. For that aim 28 mail patients (mean age 51.8 years), treated with 45 Gy using the conventional 3 field technique were selected and subjected to retrospective dosimetric study using the avoiding divergence technique. Significant statistical difference was showed between the two proposed techniques (5.66 Gy, $3.53 \mathrm{~Gy}$; p <0.0001) in favour of avoiding divergence technique (median of the min-imum doses to the testicles: $0.20 \mathrm{~Gy}, 0.09 \mathrm{~Gy}$ and the median of the maximum doses to the testicles: $15.32 \mathrm{~Gy}, 14.00 \mathrm{~Gy}$ ). Patients with rectal cancer who are going to receive radiotherapy treatment with conventional radiotherapy tech-nique, are at risk of permanent infertility. This paper presents conventional ra-diotherapy technique, for the patients with rectal cancer which will, due to re-duction of medium testicular dose, reduce the risk of infertility.
\end{abstract}

\section{Introduction}

Colon and rectum cancer is the third of all cancers by its incidence. It is in second place by the mortality caused by cancer. Colorectal cancer is the most frequent type of cancer after breast cancer and ovarian cancer in women and lung cancer in male [1]. At least $60 \%$ of patients with rectal cancer can expect long-term survival after multi-modal treatment. About $80 \%$ of male patients were sexually active at the time of di-agnosis of rectal cancer, but often develop sexual dysfunction [2]. Radiotherapy treatment is recommended for patients to improve local control of the disease $[3,4]$. Sexual dysfunction often occurs after external radiotherapy $[5,6]$.

During radiation testicles are normally outside the radiation target volume, however they may be ex-posed to scatter radiation. In the low-passed rectal cancers testicles may be in the field of radiation, and exposed to direct radiation. The magnitude of scatter radiation de-pends on the distance from the border of radiation field to the testicles [2]. Therefore, the radiotherapy treatment of rectal cancer causes significant damage to the testicles. Most of the dose is delivered using AP-PA fields, due to the divergence of AP-PA fields to the testicles [7,8]. If we take into account that the majority of male patients with rectal cancer are younger and middle age, sexual dysfunction is a serious prob-lem associated with the dose their testicles receive during the treatment [9]. There is a significant heterogeneity in access to modern radiotherapy equipment in Europe. While in the countries of Northern and Western Europe modern radiotherapy equip-ment is available, other countries face significant disadvantages in equipment. In par-ticular, there is a lack of machinery capable of delivering high precision conformal treatment (IMRT, IGRT) [10]. In contrary, $57 \%$ of all cancers (excluding non-melanoma skin cancer) occur in less developed countries and $43 \%$ in more developed countries [11]. In the Balkans there are many centers that irradiate rectal cancer with conventional technique. The conventional technique involves a technique with 3 or 4 pelvic fields. The technique with 3 fields using wedges gets homogeneous distribution within irradiated volume, while the technique with 4 fields (the box technique) does not use wedges. Both techniques have a problem with divergence of the fields to-wards the testicles.

The aim of this study is to compare the dose to the testicles of radiotherapy course for rectal cancer by conventional techniques and radiotherapy course for rectal cancer conventional technique with avoidance divergence of the fields towards the testicles.

\section{Materials and methods}

We selected the 28 male patients treated in the period of three years at the Univer-sity Clinical Centre Tuzla. Primary rectal cancer was diagnosed to patients. The ex-clusion criteria for selected patients, was an age over 60 years. The prescribed dose for the radiotherapy treatment was $45 \mathrm{~Gy}$. All patients underwent CT simulation in the prone position with the use of a belly board pad immobilization tool. Patients were scanned from the L2 / L3 boundary to $2 \mathrm{~cm}$ below the outer border of the testicles with a thickness of $5 \mathrm{~mm}$ scan. On FOCAL planning system, a conventional plan with three fields (3FCRT - 3fields conventional radiation therapy) was made: one posterior (PA) and two lateral fields - right lateral (RLAT) and left lateral (LLAT) (Figures 1 and 2).

${ }^{\star}$ Correspondence to: Edis Dedovic, Depertment of medical physics and radiation protection, University Clinical Centre Tuzla, Ul. prof. dr. Ibre Pašića, Tuzla 75000, Bosnia and Herzegovina, Tel: +38761675094; E-mail: edis.djedovic@yahoo.com

Key words: conventional radiotherapy, rectal cancer, testicular dose

Received: November 13, 2018; Accepted: November 23, 2018; Published: November 26, 2018, 2018 
The calculation of the dose distribution was made on $\mathrm{XiO}$ treatment planning system (TPS). The specifications of the treatment fields were presented in Table 1.

Retrospectively, for each patient the delineation of testicles and a treatment plan prep-aration were made using the same treatment fields. On this way the divergence of the fields was avoided. Field divergence avoidance has been used routinely during irradi-ation of breast with supraclavicular lymph nodes. Avoiding divergence in this case has been achieved by rotating the table, or using the half field beams. In patients treated in this study, because of the size of pelvic fields, avoiding the divergence of the field was achieved by rotating a treatment table (3FCDRT - 3field conventional divergence radiation therapy) (Figures 3 and 4$)$.

The aim was, by rotating the table, to bring the edges of all three fields into one axial plane. The specifications of the treatment fields were presented in Table 2. The speci-fications of the treatment fields of a three fields conventional divergence radiation therapy. Same geometry of the fields and MLC protection was retained.

The dose volume histograms (DVHs) for testicles were calculated and the mean, max-imum and minimum doses, to the testicles, were

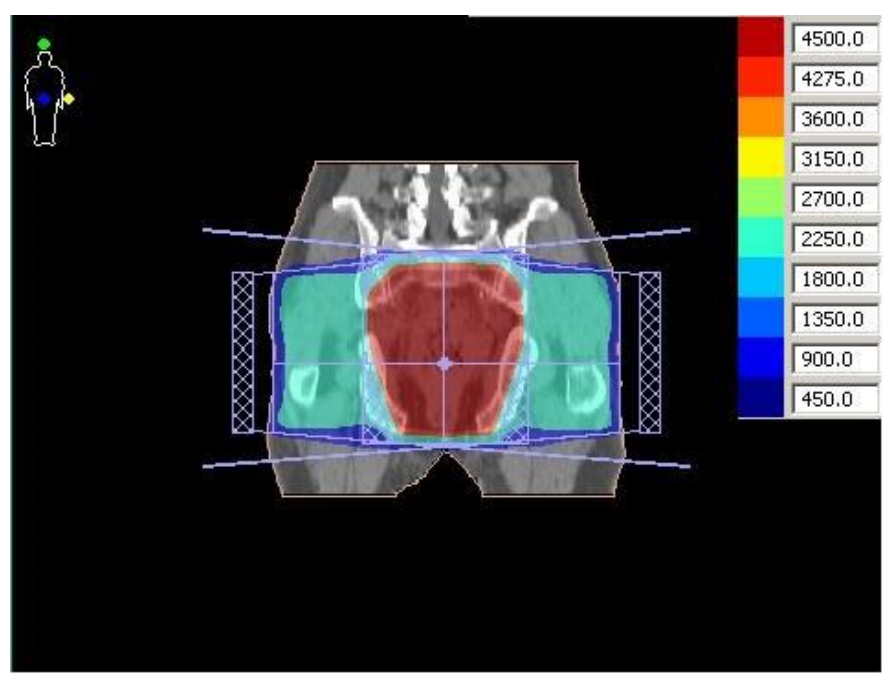

Figure 1. 3FCRT set up of fields-coronal view

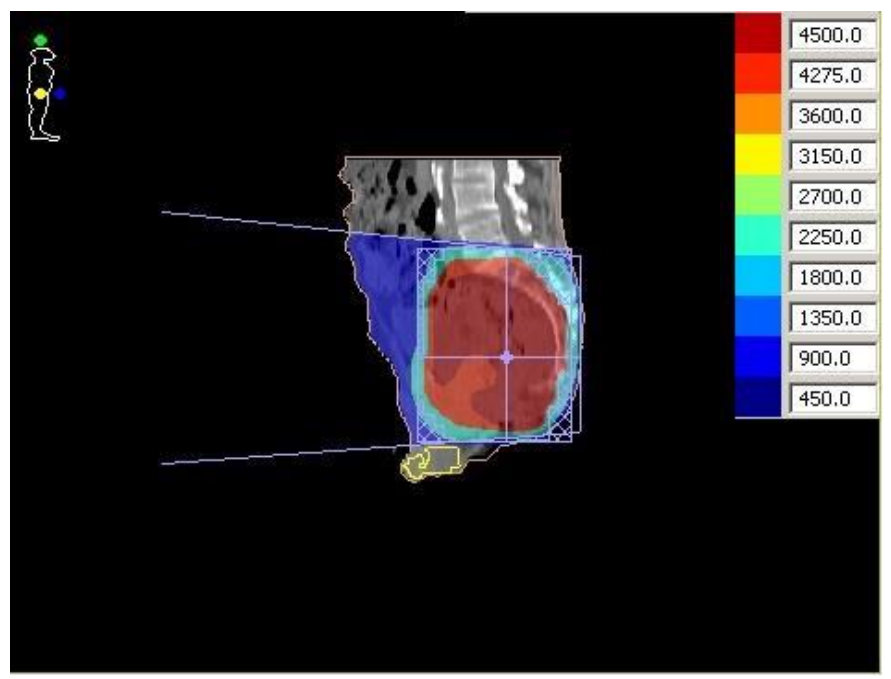

Figure 2. 3FCRT set up of fields-sagital view
Table 1. The specifications of the treatment fields of a conventional plan

\begin{tabular}{|c|c|c|c|c|c|}
\hline Field & $\begin{array}{c}\text { Beam } \\
\text { energy } \\
\text { (MV) }\end{array}$ & $\begin{array}{c}\text { Gentry } \\
\text { angle } \\
\text { (degrees) }\end{array}$ & $\begin{array}{c}\text { Collimator } \\
\text { angle } \\
\text { (degrees) }\end{array}$ & $\begin{array}{c}\text { Couch angle } \\
\text { (degrees) }\end{array}$ & $\begin{array}{c}\text { Wedge } \\
\text { (degrees) }\end{array}$ \\
\hline PA & 15 & 0 & 0 & 0 & - \\
\hline RLAT & 15 & 270 & 90 & 0 & 40 \\
\hline LLAT & 15 & 90 & 270 & 0 & 40 \\
\hline
\end{tabular}

Table 2. The specifications of the treatment fields of a three fields conventional divergence radiation therapy

\begin{tabular}{|c|c|c|c|c|c|}
\hline Field & $\begin{array}{c}\text { Beam energy } \\
\text { (MV) }\end{array}$ & $\begin{array}{c}\text { Gentry angle } \\
\text { (degrees) }\end{array}$ & $\begin{array}{c}\text { Collimator } \\
\text { angle } \\
\text { (degrees) }\end{array}$ & $\begin{array}{c}\text { Couch angle } \\
\text { (degrees) }\end{array}$ & $\begin{array}{c}\text { Wedge } \\
\text { (degrees) }\end{array}$ \\
\hline PA & 15 & 5 to 7 & 90 & 90 & - \\
\hline RLAT & 15 & 270 & 90 & 354 to 356 & 40 to 50 \\
\hline LLAT15 & & 90 & 270 & 4 to 6 & 40 to 50 \\
\hline
\end{tabular}

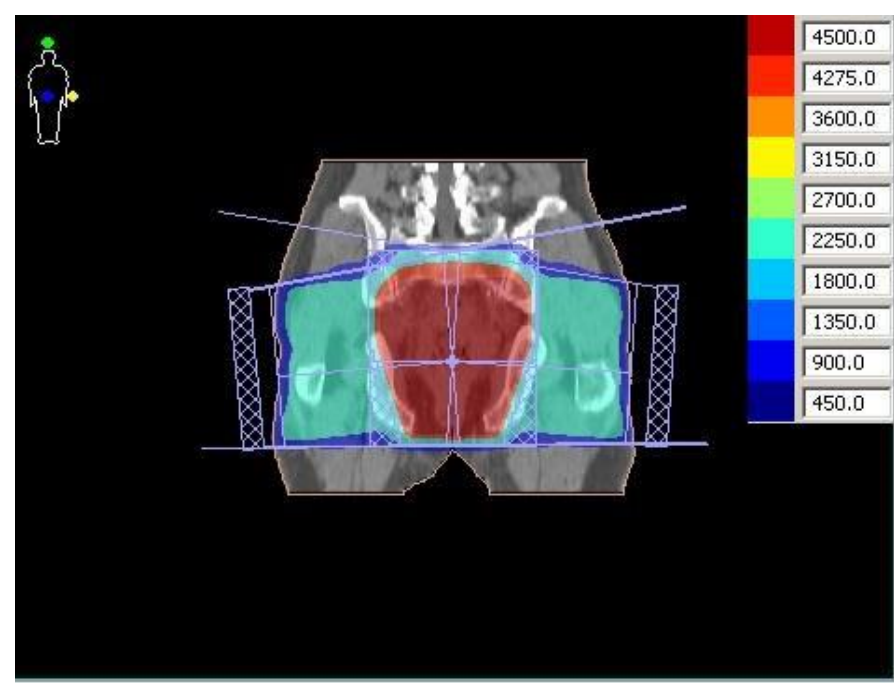

Figure 3. 3FCDRT set up of fields-coronal view

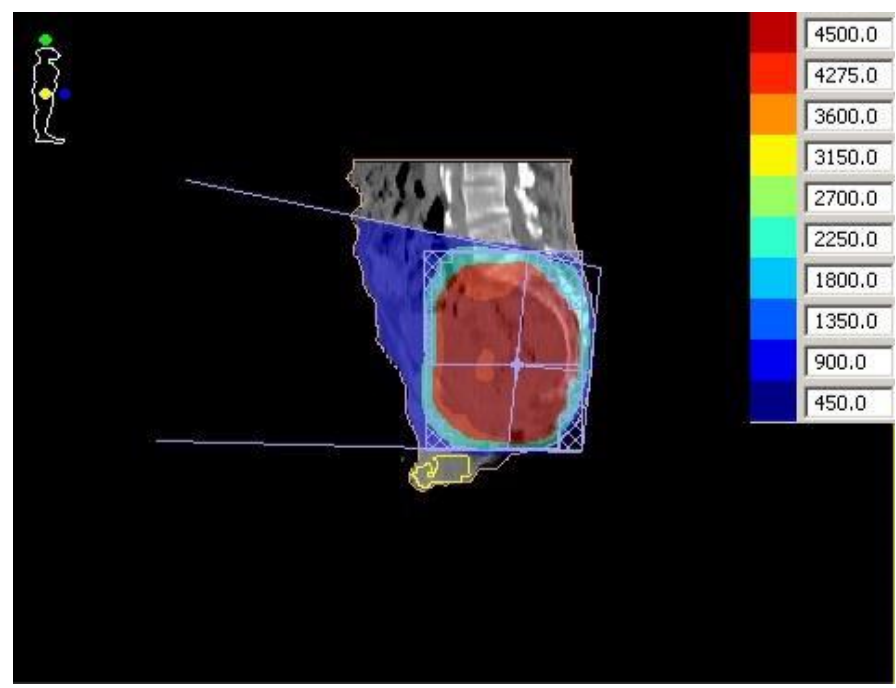

Figure 4. 3FCDRT set up of fields-sagital view

compared. The maximum and mini-mum doses correspond to the dose in one voxel.

A statistical analysis was performed with Graph Pad Prism software. Two-tailed paired t test was used with level of statistical significance of 
$\mathrm{p}<0.05$. Results show the median, minimum and a maximum value of the variables, and statistical signifi-cance $\mathrm{p}$.

\section{Results}

For 28 selected male patients with radiotherapy treatment of rectal cancer, a com-parison of 3FCRT and 3FCDRT planning techniques was performed. The mean age of patients was 51.8 years with a range of 34-60 years. The results show a statistically significant difference between dose to the testicles received by 3FCRT and 3FCDRT. Table 1 summarizes the characteristics of various planning techniques. There is sig-nificant statistical difference between the two proposed techniques ( $p<0.0001$ ) in favour of avoiding divergence to the testicles technique. If considering the median of the minimum doses to the testicles, 0.20 Gy (0 Gy-6.75 Gy), 0.09 Gy (0 Gy-4.49 Gy) and the median of the maximum doses to the testicles, $15.32 \mathrm{~Gy}(0.63 \mathrm{~Gy}-22.43 \mathrm{~Gy}) 14.00 \mathrm{~Gy}$ (0.51 Gy-20.48 Gy), a statistical difference $(\mathrm{p}=0.0091$ and $\mathrm{p}=0.0013)$ in favour of avoiding divergence to the testicles technique was showed. However, we noticed a higher maximum value of medium dose to the testicles with 3FCDRT than in 3FCRT (15.24 Gy vs. 15.14 Gy). Namely, when the testicles are in the field of radiation by their entire volume, turning the table and gantry for PA field will increase contribution of dose to the testicles, due to the fact that, even partial volume of the testicles is not coming out of the radiation field.

In addition, reducing the dose to the testicles leads to an increase in dose to the small bowel. The difference between the two plans indicates an increase in dose to the small bowel of up to $15 \%$. Within the target volume bounded with three fields there is no difference in dose greater than 5\% Figure 5.

\section{Conclusions}

The developed countries are using the advanced radiation techniques (IMRT, VMAT) for radiotherapy treatment of rectal. In less developed countries, mainly is in use conventional radiation technique for rectal cancer. During radiotherapy treatment with use of conventional radiation technique testicles may be exposed to direct or scattered radiation. It causes the male patients, often younger age, after radiotherapy treatment, have lower level of testosterone compared to the pre-treatment level or with patients subjected only to the surgical treatment. A reduced level of testosterone contributes to sexual dysfunction [2]. There are many studies that determined the effect of radiation on the level of male sex hormones $[9,12,13]$. Mazonakis, et al. measured scattered testicular dose of radiation during radiotherapy

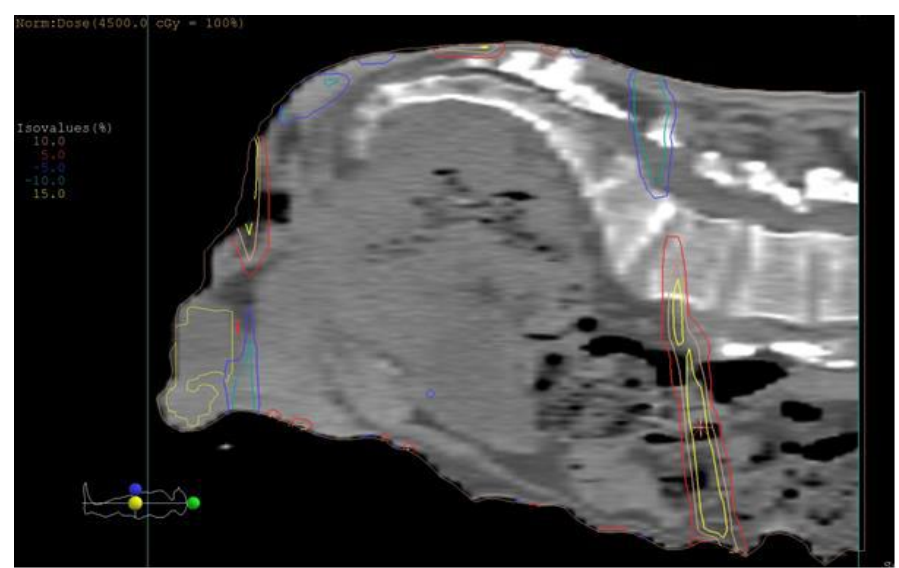

Figure 5. 3FCDRT small bowel increase in dose treatment [14]. They irradiated phantom with $6 \mathrm{MV}$ photon beams and examined the influence of various factors of radiotherapy treatment. They offered the equation for estimating testicular dose taking into account the number of fields, beam weight, field size, wedge, a distance of testicles from field isocentre, and tissue thickness along the beam axis. The mean difference between in vivo measured doses to the testicles and doses calculated by proposed equation was $5.8 \%$. Mazonakis showed that gonadal shields significantly reduce the dose to the testicles. However, if the gonadal shields are in the field of radiation, due to the production of secondary electrons, the testicular dose can increase [15]. Piroth, et al. performed measurements of scattered testicular dose during radiotherapy treatment for rectal cancer. The measurements were performed using TLDs on the testicles of 18 patients. Patients were treated with 3 field's tech-nique. Estimated cumulative mean dose to the testicles was 1.6 Gy. However, they proved that variations in measured doses during these measurements can be significant. The possible reasons were the dosimeter has been moved or the testicles have been in different position during the treatment session [16]. Various studies have shown that the distance of the testicles from the lower border of the radiation field is the most important factor affecting testicular dose [8,14,17-19]. Herman, et al. showed that the percentage of the dose testicles received due to the scattered radiation is inversely proportional to the distance of the testicles from the lower border of the radiation field [8]. In comparison of the three fields technique and four fields tech-nique, also prone and supine with aim to reduce testicular dose, some authors prefer radiotherapy course in supination with 4 fields technique [20]. Our study was carried out with three fields technique, but the principle is applicable to the four fields technique.

Our results show that the use of avoiding fields divergence radiotherapy techniques of radiation to the testicles, the mean testicular dose can be reduced. In centres where advanced techniques of radiation are not available, patients with rectal cancer who will receive the radiotherapy treatment are at risk of permanent infertility. We presented radiotherapy technique for the patients with rectal cancer that will, due to re-duction of medium testicular dose, reduce the risk of infertility. Although this tech-nique slightly increases the dose to the small intestines, it can be an option technique, especially in younger patients.

\section{References}

1. Beyzadeoglu M, Ozyigit G, Ebruli C (2010) Basic Radiation Oncology. Springer Berlin Heidelberg.

2. Buchli C, Martling A, Arver S, Holm T (2011) Testicular function after radiotherapy for rectal cancer-a review. J Sex Med 8: 3220-3226. [Crossref]

3. Cedermark B (1995) The Stockholm I trial of preoperative short term radiotherapy in op-erable rectal carcinoma. A prospective randomized trial. Stockholm Colorectal Cancer Study Group. Cancer 75: 2269-2275.

4. Martling A, Holm T, Johansson H, Rutqvist LE, Cedermark B (2001) Stockholm Colorectal Cancer Study Group. The Stockholm II trial on preoperative radiotherapy in rectal carcinoma: long-term follow-up of a population-based study. Cancer 92: 896902

5. Lange M, Marijnen CA, Maas CP, Putter H, Rutten HJ, et al. (2009) Cooperative Clinical Investigators of the Dutch. Risk factors for sexual dysfunction after rectal cancer treatment. Eur J Cancer 45: 1578-1588.

6. Lange MM, Van De Velde CJ (2011) Urinary and sexual dysfunction after rectal cancer treatment. Nat Rev Urol 8: 51

7. Hennies S, Wolff HA, Jung K, Rave-Fränk M, Gaedcke J, et al. (2012) Testicular radiation dose after multimodal curative therapy for locally advanced rectal cancer. Strahlenther Onkol 188: 926-932. 
8. Hermann RM, Henkel K, Christiansen H, Vorwerk H, Hille A, et al. (2005) Testicular dose and hormonal changes after radiotherapy of rectal cancer. Radiother Oncol 75: 83-88.

9. Dueland S, Guren MG, Olsen DR, Poulsen JP, Tveit KM (2003) Radiation therapy induced changes in male sex hormone levels in rectal cancer patients. Radiother Oncol 68: 249-253.

10. Grau C, Defourny N, Malicki J, Dunscombe P, Borras JM, et al. (2014) Radiotherapy equipment and departments in the European countries: final results from the ESTROHERO survey. Radiother Oncol 112: 155-164. [Crossref]

11. World Cancer Research Fund Internatonal (2017). Retrieved from http://www.wcrf.org.

12. Yoon FH, Perera F, Fisher B, Stitt L (2009) Alterations in hormone levels after adjuvan chemoradiation in male rectal cancer patients. Int J Radiat Oncol Biol Phys 74: 11861190 .

13. Zagars GK, Pollack A (1997) Serum testosterone levels after external beam radiation for clinically localized prostate cancer. Int J Radiat Oncol Biol Phys 39: 85-89.

14. Mazonakis M, Kokona G, Varveris H, Damilakis J, Gourtsoyiannis N (2006) Data required for testicular dose calculation during radiotherapy of seminoma. Med Phys 33: 2391-2395. [Crossref]
15. Nazmy MS, El-Taher MM, Attalla EM, El-Hosiny HA, Lotayef MM (2007) Shielding for scattered radiation to the testis during pelvic radiotherapy: is it worth? J Egypt Natl Canc Inst 19: 127-132. [Crossref]

16. Piroth MD, Hensley F, Wannenmacher M, Zierhut D (2003) Male gonadal dose in adjuvant 3-d-pelvic irradiation after anterior resection of rectal cancer. Influence to fertility. Organ der Deutschen Rontgengesellschaft...[et al]. Strahlenther Onkol 179: 754-759.

17. Amies CJ, Mameghan H, Rose A, Fisher RJ (1995) Testicular doses in definitive radiation therapy for localized prostate cancer. Int J Radiat Oncol Biol Phys 32: 839846

18. Budgell GJ, Cowan RA, Hounsell AR (2001) Prediction of scattered dose to the teste in abdominopelvic radiotherapy. Clin Oncol (R Coll Radiol) 13: 120-125. [Crossref]

19. Martin JM, Handorf EA, Price RA, Cherian G, Buyyounouski MK, et al. (2015) Comparison of testicular dose delivered by intensity-modulated radiation therapy (IMRT) and volumetric-modulated arc therapy (VMAT) in patients with prostate cancer. Med Dosim 40: 186-189. [Crossref]

20. Bakkal BH, Vural T, Elmas O, Yildiz O, Kokturk F (2014) Effect of treatment position and radiotherapy planning on testicular dose in patients with rectal carcinoma. $J$ Cancer Res Ther 10: 558 .

Copyright: (C2018 Osmic H. This is an open-access article distributed under the terms of the Creative Commons Attribution License, which permits unrestricted use, distribution, and reproduction in any medium, provided the original author and source are credited. 